\title{
COMPETÊNCIAS REQUERIDAS ÀS CHEFIAS INTERMEDIÁRIAS DA PRODEGESP/UFSC: DO MAPEAMENTO À CAPACITAÇÃO ${ }^{1}$
}

\author{
Mônica Scóz Mendes ${ }^{2}$ \\ Kelly Cristina Benetti Tonani Tosta ${ }^{3}$
}

http://dx.doi.org/10.1590/1413-2311.219.84478

\section{RESUMO}

Este estudo tem por objetivo analisar como desenvolver as competências requeridas aos gestores de nível intermediário da Pró-Reitoria de Desenvolvimento e Gestão de Pessoas (PRODEGESP) da Universidade Federal de Santa Catarina (UFSC). A pesquisa foi aplicada, descritiva e de caráter qualitativo. Apresentou características de pesquisa bibliográfica, documental, pesquisa de campo e estudo de caso. Para a coleta de dados, fez-se uso de observação, entrevistas semiestruturadas e aplicação de questionário. Para a sua análise, utilizou-se o estudo da fala dos entrevistados e a aplicação da Escala Likert. Os dados obtidos evidenciam que as competências requeridas aos gestores são também por eles apresentadas, destacando um pequeno gap (lacuna) quando seus graus são avaliados. A partir desse gap, foram levantadas as sete competências mais relevantes, para as quais foram propostas ações de capacitação. Por fim, recomenda-se que outros estudos sejam realizados, evidenciando mudanças e/ou estagnações tanto das competências quanto da realidade vivenciada. Ademais, importante mencionar que a metodologia utilizada neste estudo pode ser replicada por outras Pró-Reitorias da UFSC com estruturas funcionais semelhantes à PRODEGESP, haja vista a

\footnotetext{
${ }^{1}$ Recebido em 03/07/2018; aprovado em 20/12/2018.

2 Universidade Federal de Santa Catarina (UFSC) - Programa de Pós-Graduação em Administração Universitária (PPGAU); Florianópolis - SC (Brasil) - monica.scoz@ufsc.br

${ }^{3}$ Universidade Federal da Fronteira Sul (UFFS), Campus Chapecó - Curso de Administração; Universidade Federal de Santa Catarina (UFSC), - Programa de Pós-Graduação em Administração Universitária (PPGAU); Florianópolis - SC (Brasil) - kellycbenetti@gmail.com
} 
relevância do cargo ocupado junto ao dirigente máximo e também junto à sociedade de uma maneira geral.

Palavras-chave: Competências. Chefias Intermediárias. Desenvolvimento de Competências.

\title{
COMPETENCES REQUIRED FOR INTERMEDIATE MANAGERS AT PRODEGESP/UFSC: FROM MAPPING TO TRAINING
}

\begin{abstract}
This study aims to analyze how to develop the competences required to middle managers at the Pro-Rectory of Development and People Management (PRODEGESP) of Federal University of Santa Catarina (UFSC). The research was applied, descriptive, with qualitative character. It presented bibliographic, documental, field research and case study characteristics. For data collect, besides documental and bibliographic analysis, observation was used, as well as semi-structured interviews and questionnaires. To analyze the collected data, the speeches of the interviewee were studied, and Likert Scale was applied. These collected data evidenced that the competences required to middle managers are also shown by them at their performances, presenting a small gap when compared. From this gap, seven competences were selected as the most relevant, to which training actions were suggested. At last, it is recommended other studies involving this thematic, evidencing changes and/or stagnations to both competences and the reality experienced. In addition, it is important to mention that the methodology used in this study can be replied at different Pro-Rectories at UFSC, regarding its similarities to PRODEGESP, since this study showed the relevance of the middle manager role for the higher manager and also to society in general.
\end{abstract}

Keywords: Competences. Middle Managers. Competence Development. 


\title{
COMPETENCIAS REQUERIDAS A LAS CHEFÍAS INTERMEDIARIAS DE LA PRODEGESP / UFSC: DEL MAPEO A LA CAPACITACIÓN
}

\begin{abstract}
RESUMEN
Este estudio tiene por objetivo analizar cómo desarrollar las competencias requeridas a los gestores de nivel intermedio de la Pro-Rectoría de Desarrollo y Gestión de Personas (PRODEGESP) de la Universidad Federal de Santa Catarina (UFSC). La investigación fue aplicada, descriptiva y de carácter cualitativo. Presentó características de investigación bibliográfica, documental, investigación de campo y estudio de caso. Para la recolección de datos, se hizo uso de observación, entrevistas semiestructuradas y cuestionario. Para su análisis, se utilizó el estudio del habla de los entrevistados y la aplicación de la Escala Likert. Los datos obtenidos evidencian que las competencias requeridas a los gestores son también por ellos presentadas, destacando un pequeño gap (laguna) cuando sus grados son evaluados. A partir de ese gap, se levantaron las siete competencias más relevantes, para las cuales se propusieron acciones de capacitación. Por último, se recomienda que otros estudios sean realizados, evidenciando cambios y/o estancamientos tanto de las competencias como de la realidad vivenciada. Además, es importante mencionar que la metodología utilizada en este estudio puede ser replicada por otras Pro-Rectorías de la UFSC con estructuras funcionales semejantes a la PRODEGESP, teniendo en cuenta la relevancia del cargo ocupado junto al dirigente máximo y también junto a la sociedad de una manera general.
\end{abstract}

Palabras-clave: Competencias. Gestores Intermediarios. Desarrollo de Competencias.

\section{INTRODUÇÃO}

Há muito se fala sobre as pessoas dentro das organizações, sejam elas executoras de tarefas operacionais ou ocupantes dos mais altos cargos decisivos. Aos poucos, as organizações vêm adotando uma postura mais proativa e planejada em relação às mudanças, realidade que abrange tanto organizações privadas quanto públicas, haja vista a forte demanda da população e da imprensa com relação ao nível de qualidade dos serviços prestados, levando o Estado também a experimentar a necessidade de mudanças em sua estrutura (ROCHA; SHINYASHIKI; PASSADOR, 2012). 
Aliado a este fato, percebe-se, nas organizações públicas, uma crescente valorização das pessoas, o que pode ser atribuído às mudanças constantes e à necessidade de respostas mais rápidas para questões mais complexas, como as novas formas de organização do trabalho e a mudança de postura das pessoas (DALMAU, 2014).

Diante desse contexto, é categórico que se pense na consolidação das habilidades e potenciais das pessoas que compõem as organizações, buscando inserir em sua filosofia e estrutura um novo conceito de trabalho, bem como os desafios a ele inerentes (ARAÚJO; GALEANO; VIEIRA, 2015). Diante desses novos desafios, já no início deste século, Grillo (2001, p. 13), ressaltava que a Universidade, sendo parte desta Administração Pública, tem que se preparar para dar maior atenção à gestão do seu pessoal, no sentido de propiciar condições adequadas para que professores, pesquisadores, técnicos e administradores desenvolvam suas funções de maneira harmoniosa e eficaz, num clima de colaboração mútua,

Trazendo essa discussão à realidade organizacional proposta nesse estudo, vê-se que, na Administração Pública Federal, a gestão por competências foi introduzida pelo Decreto $\mathrm{n}^{\circ}$ 5.707, de 23 de fevereiro de 2006 (BRASIL, 2006), que instituiu a Política Nacional de Desenvolvimento de Pessoal - PNDP, a ser implantada pelos órgãos da administração pública federal. O Decreto em questão tem como finalidade a adequação das competências exigidas dos servidores aos objetivos das instituições e especifica novos métodos e técnicas de capacitação e desenvolvimento (BRASIL, 2006).

Este Decreto foi posteriormente complementado pela Portaria $n^{\circ} 208$, de 25 de julho de 2006, que apresentou os instrumentos da PNDP, quais sejam: Plano Anual de Capacitação, Relatório de Execução do Plano Anual de Capacitação e Sistema de Gestão por Competências

(BRASIL, 2006a).

Entretanto, Sartoretto (2016) igualmente afirma que, apesar desses dois marcos legais, no serviço público, a eficácia da gestão por competências ainda necessita de discussões mais aprofundadas. Desta forma, vê-se, nesta pesquisa, uma possiblidade de qualificação dos servidores para o seu desempenho no trabalho por meio do mapeamento das competências requeridas aos seus gestores e da proposta de ações de capacitação. Com o intuito de direcionar a pesquisa, optou-se por trabalhar com um nicho específico de servidores, aqui denominado como "chefias intermediárias", selecionando os gestores de nível intermediário da Pró-Reitoria de Desenvolvimento e Gestão de Pessoas da Universidade Federal de Santa Catarina (PRODEGESP/UFSC) que possuem relação de trabalho direta com a chefia máxima (Pró-Reitora), e também com os demais servidores a ele subordinados, chegando-se, desta 
forma, aos diretores dos departamentos. Desta forma, tem-se como objetivo da pesquisa analisar como desenvolver as competências requeridas aos gestores de nível intermediário da PRODEGESP/ UFSC.

Com relação às suas justificativas, esta pesquisa mostrou-se importante, visto que buscou identificar quais as competências necessárias aos gestores ocupantes de cargos de chefia, comparou as competências requeridas às competências reais e propôs um caminho para desenvolver os servidores. Além de importante, a pesquisa revelou-se também oportuna, já que foi realizada em consonância com a sua missão da Pró-Reitoria, contribuindo com a política de gestão de pessoas da UFSC, onde se esperou trazer à tona evidências que proporcionem sua efetiva melhoria. Ainda com relação à oportunidade, cabe aqui ressaltar que o estudo permite à UFSC e, mais especificamente, à PRODEGESP a aplicação da legislação vigente acerca da gestão por competências. Por fim, ressalta-se, ainda, a viabilidade desta pesquisa, uma vez que houve amplo acesso aos gestores e às suas informações e sua execução não trouxe ônus financeiros.

\section{FUNDAMENTAÇÃO TEÓRICA}

\subsection{GESTÃO DE PESSOAS NA UNIVERSIDADE}

As Universidades, enquanto comunidades relativamente autônomas de professores e alunos reunidos para assegurar o ensino de nível superior, remetem ao início do Século XIII, na Europa (TOSTA, 2011). No Brasil, o surgimento da instituição Universidade remete aos Séculos XVI, XVII e XVIII, período em que os cursos superiores serviram à qualificação das elites agrárias e à classe dominante (SOUZA, 1996). Oficialmente, de acordo com Fávero (2006), considera-se como primeira universidade brasileira a Universidade do Rio de Janeiro - URJ, criada em 1920.

Desde então, novas universidades têm sido criadas, o que, para Grillo (2001, p. 09), tem aumentado o interesse para a "criação de sistemas administrativos que possam propiciar melhores níveis de qualidade ao ensino superior e à pesquisa, tendo em vista, principalmente, o alto grau de complexidade dessas instituições". Trazendo a discussão para o ambiente universitário e os indivíduos que ali trabalham, foco da presente pesquisa, Grillo (2001) ratifica que, mesmo sendo objeto de abordagens em encontros acadêmicos no Brasil, a política de pessoal das Universidades não tem, ainda, recebido tratamento adequado, 
impedindo, assim, o melhor aproveitamento das potencialidades dos seus servidores, além de prejudicar, sensivelmente, o seu desempenho.

Souza e Kobiyama (2010) afirmam que é fundamental que se estabeleça uma política de gestão de pessoas nas organizações, especialmente no ambiente universitário, no qual podem ser criadas e desenvolvidas novas formas de ensinar, pesquisar e levar conhecimento à sociedade. Assim, é de fundamental importância a implantação de um modelo de gestão de pessoas que "facilite a adoção dos princípios da administração gerencial e capacite os servidores para que eles sejam agentes estratégicos de mudança das organizações públicas" (ANDRADE; SANTOS, 2004, p. 3).

Ampliando a discussão, vê-se que, nas universidades federais brasileiras, a gestão de pessoas está fundamentada no cumprimento das legislações federais que versam sobre o tema, tendo como principal baliza a Lei $\mathrm{n}^{\circ} 8.112$, de 1990, que dispõe sobre o regime jurídico dos servidores públicos civis da União, das autarquias e das fundações públicas federais (BRASIL, 1990). No entanto, diversas são as legislações complementares a esta que tratam de assuntos como avaliação de desempenho, progressão funcional e, mais recentemente, da gestão por competências na administração pública federal (TOSTA, 2011).

Dentre as políticas estabelecidas no âmbito federal para a gestão de pessoas, destacase a já comentada Política Nacional e Desenvolvimento de Pessoal (PNDP), instituída pelo Decreto $n^{\circ}$ 5.707, de 2006 (BRASIL, 2006). A citada política tem como finalidade a melhoria da eficiência, eficácia e o nível de qualidade dos serviços públicos prestados ao cidadão por meio do desenvolvimento permanente do servidor público, e adequação das competências requeridas dos servidores aos objetivos das instituições das quais eles fazem parte (BRASIL, 2006). Para basear a sua implementação, a PNDP apresenta treze diretrizes, dentre as quais se destacam as ações de capacitação aos servidores públicos, estimulando a sua participação em atividades de educação continuada e avaliação periódica dos resultados dessas ações de capacitação.

\subsection{COMPETÊNCIAS}

No final da Idade Média, o termo competência pertencia essencialmente à linguagem jurídica. Dizia respeito à faculdade atribuída a uma pessoa ou a uma instituição para apreciar e julgar certas questões. Por extensão, a expressão passou a designar o reconhecimento social sobre a capacidade de alguém em se pronunciar acerca de determinado assunto e, ainda mais 
tarde, passou a ser utilizada também para qualificar o indivíduo capaz de realizar certo trabalho (BRANDÃO; BORGES-ANDRADE, 2007).

De forma estruturada, o conceito de competência foi proposto pela primeira vez por David McClelland, que buscava uma abordagem mais efetiva para os processos de escolha de pessoas para as organizações (FISCHER et. al., 2010). Entretanto, não obstante a possibilidade de interpretar a competência de múltiplas maneiras, Dutra (2007) afirma que é possível perceber a existência de duas grandes correntes teóricas: a primeira, representada por autores norte-americanos, entende a competência como um conjunto de qualificações do indivíduo, que permitem a ele realizar determinado trabalho; a segunda, defendida pelos autores franceses, associa a competência às realizações do indivíduo em um contexto, ou seja, aquilo que ele produz ou realiza no trabalho (DUTRA, 2007).

Segundo Brandão e Borges-Andrade (2007), desde o início dos anos 2000, uma terceira vertente tem obtido destaque, buscando adotar uma postura integradora, ao definir a competência a partir da junção de concepções das referidas correntes. Neste cenário, competência é entendida, então, como o conjunto de Conhecimentos (saber), Habilidades (saber fazer) e Atitudes (querer fazer) - CHA - necessários para exercer determinada atividade aliado ao desempenho expresso em um contexto produtivo, agregando valor às pessoas e às organizações (BRANDÃO; BORGES-ANDRADE, 2007).

Neste trabalho, entendendo que o contexto público aqui analisado exerce grande influência sobre o conjunto CHA analisado, optou-se por seguir essa terceira corrente teórica apresentada, unindo a literatura norte-americana com a francesa, tomando por base a definição de competência expressa no Decreto 5.707/2006: conjunto de conhecimentos, habilidades e atitudes necessárias ao desempenho das funções dos servidores, visando ao alcance dos objetivos da instituição (BRASIL, 2006). Esta escolha se deu por entender que essa concepção abrange os constructos teóricos que fundamentam o trabalho e também elucida o contexto público no qual ele é realizado.

Com relação aos seus tipos, Carbone et. at. (2009) destacam que, dependendo da abordagem teórica adotada ou da finalidade a que se destina, existem diversas tipologias e possibilidades de classificação das competências. Brandão (2012) ratifica essa ideia quando afirma que, assim como existem diferentes abordagens e conceitos para o significado do termo competências, há também diferentes classificações das competências em si. Desta forma, para fins de delimitação do campo de pesquisa, optou-se por trabalhar com três tipos delas, quais sejam: (a) competências organizacionais - conjunto de conhecimentos, habilidades, tecnologias e comportamentos que uma organização possui e consegue 
manifestar de forma integrada na sua atuação (HARB, 2005); (b) competências individuais combinações sinérgicas de conhecimentos, habilidades e atitudes, expressas pelo desempenho profissional dentro de determinado contexto ou estratégia organizacional (BRANDÃO; BAHRY, 2005); (c) competências Gerenciais - capacidade de mobilizar diversos recursos cognitivos, como saberes, informações, habilidades e inteligências, para enfrentar e solucionar uma série de situações ou de problemas relacionados com a gestão de uma organização (PELISSARI; GONZALEZ; VANALLE, 2011).

Para Almeida (2013), as competências gerenciais são aquelas que os indivíduos devem possuir para poder ocupar uma posição gerencial em certo contexto organizacional. Em função da sua importância para o contexto do presente estudo, vale trazer à presente discussão a teoria do middle manager, ou Gerente Intermediário, que defende o papel desta chefia como um elemento articulador no processo de formação e implementação da estratégia organizacional (MACHADO; LAVARDA, 2011).

Neste cenário, o middle manager, para Nonaka (1988), é um agente ocupante de uma posição-chave na organização, dotado de capacidades para combinar estratégias em nível micro e macro, apto a eliminar ruídos e flutuações no ambiente das organizações e, ainda, atuar como um facilitador do processo de autorrenovação e mudança institucional. Dentre as principais funções deste gestor, para Lavarda, Canet-Giner e Peris-Bonet (2010), destacam-se a de defensor (comunicando e transmitindo informações da base ao topo da organização) e a de facilitador (atuando também no caminho inverso, do topo à base da organização).

Assim, trazendo a temática ao ambiente de pesquisa aqui proposto, vê-se especial importância na concepção apresentada por Pucci (2000), validada por Carletto (2006) e Ruas (2005), que entendem as competências gerenciais como a capacidade de identificar problemas e oportunidades, organizar e mobilizar os recursos disponíveis para resolvê-los, considerando capacitações mais específicas da gestão e englobando habilidades pessoais e conhecimentos de técnicas de gerenciamento.

\subsection{GESTÃO POR COMPETÊNCIAS}

Segundo Rocha, Shinyashiki e Passador (2012), com o advento da globalização e o aumento da competitividade, por volta dos anos 1990, um modelo mais estruturado de gestão de pessoas começou a ganhar força, alinhando seus moldes com as estratégias da organização. Este modelo, segundo eles (2012), caracterizado pelo maior desenvolvimento e participação dos funcionários, foi chamado Modelo de Gestão por Competências. 
De acordo com Brandão e Borges-Andrade (2007), a gestão por competências tem por objetivo aprimorar os desempenhos profissional e organizacional; ela se propõe a integrar e orientar esforços, sobretudo os relacionados à gestão de pessoas, com o intuito de desenvolver e manter competências consideradas fundamentais à consecução dos objetivos organizacionais. Este modelo de gestão tem sido apontado como uma alternativa aos instrumentos tradicionalmente utilizados pelas organizações, propondo-se, basicamente, a "gerenciar o gap ou lacuna de competências, ou seja, a reduzir ao máximo a discrepância entre as competências necessárias à consecução dos objetivos organizacionais e aquelas já disponíveis na organização" (BRANDÃO; BAHRY, 2005, p. 29).

Na Administração Pública, segundo Bergue (2011), essa matriz conceitual surgiu formalmente no Decreto 5.707/2006 (BRASIL, 2006) que define a gestão por competências como a "gestão da capacitação orientada para o desenvolvimento do conjunto de conhecimentos, habilidades e atitudes necessárias ao desempenho das funções dos servidores, visando ao alcance dos objetivos da instituição". Ainda que esta ferramenta legal aborde, de maneira limitante, a gestão por competências sob um olhar de capacitação dos servidores, sabe-se, por meio da literatura estudada, que este modelo é mais complexo, sendo composto por algumas fases, como mostra a Figura 1.

Figura 1 - Fases da gestão por competências

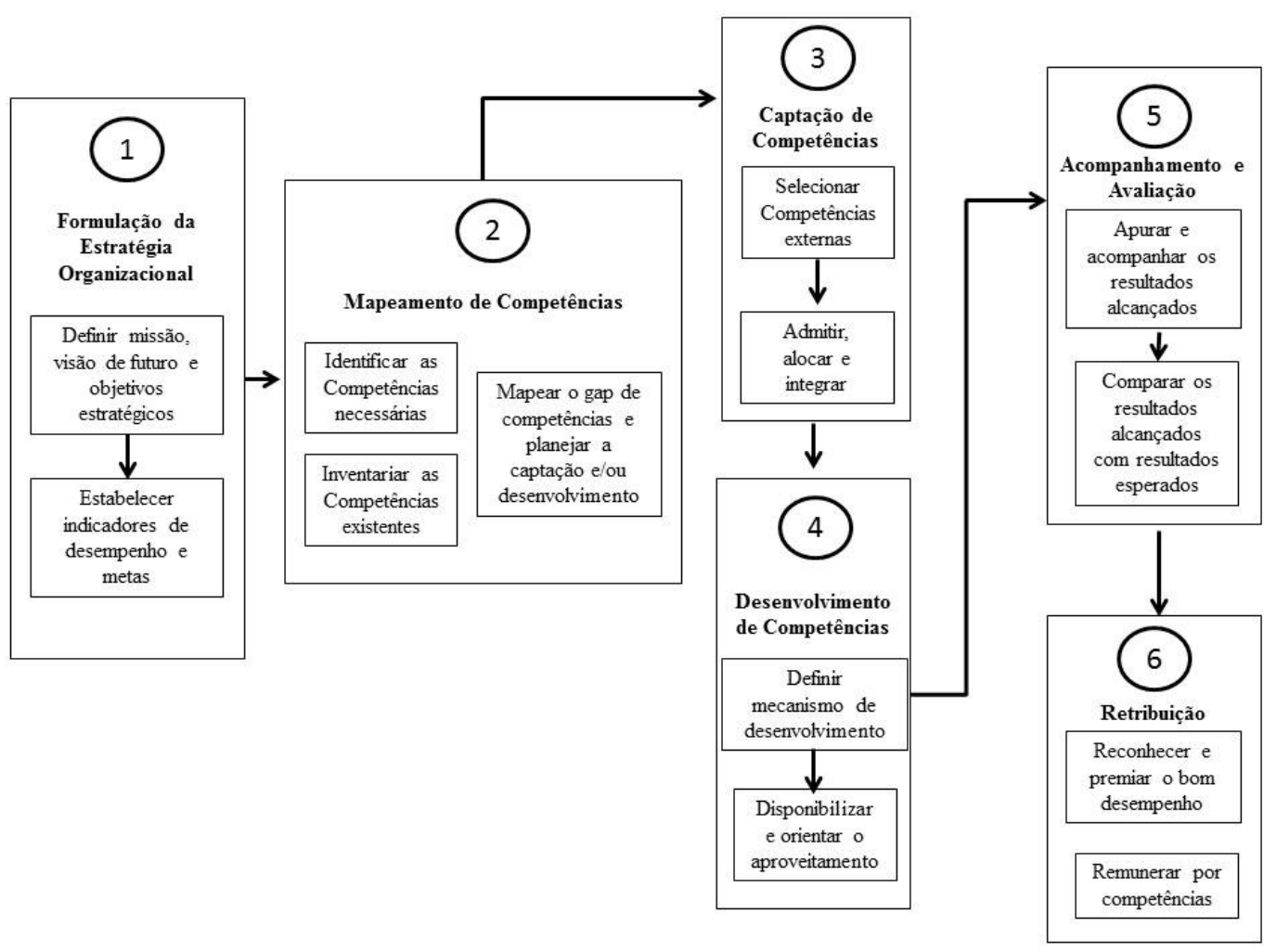

Fonte: adaptado de Brandão e Bahry (2005). 
A partir da estratégia organizacional, o modelo aqui estudado parte para o mapeamento das competências, que tem como propósito identificar o gap (lacuna) de competências, ou seja, a diferença entre as competências necessárias para atingir o objetivo ou estratégia da organização e as competências internas nela já existentes (BRANDÃO; BAHRY, 2005; CARBONE et. al., 2009). Além da identificação das competências necessárias à estratégia organizacional, o mapeamento de competências "pressupõe também inventariar as competências internas já disponíveis na organização, com o propósito de identificar a lacuna entre as competências necessárias e as já existentes na organização" (BRANDÃO; BAHRY, 2005, p. 37). Esse inventário de competências permite à organização angariar informações para o gerenciamento destas lacunas (TOSTA, 2011).

Uma vez mapeadas, parte-se à etapa seguinte, que é o seu desenvolvimento. Segundo Lana e Ferreira (2007), a gestão por competências tem, dentre as suas finalidades, o intuito de viabilizar o contínuo desenvolvimento das pessoas, contribuindo para o alcance dos objetivos organizacionais. Para Antonello e Pantoja (2001), o desenvolvimento de competências passa necessariamente pela integração e pela aplicação sinérgica dos recursos dos indivíduos e da organização nas situações. Nesse sentido, entende-se o processo de capacitação das competências como uma maneira de desenvolvê-las, no intuito de melhorar o desempenho dos profissionais e/ou da organização.

Em sua aplicação prática no serviço público, foco deste estudo, essas duas fases são expressas no inciso I, do artigo $2^{\circ}$. do Decreto $\mathrm{n}^{\circ}$. 5.707/2006, que define a capacitação como um processo permanente e deliberado de aprendizagem, com o propósito de contribuir para o desenvolvimento de competências institucionais por meio do desenvolvimento de competências individuais (BRASIL, 2006). Ao analisar essa legislação, vê-se que ela se restringe apenas ao desenvolvimento de competências, não abrangendo as demais fases do processo, o que enfraquece tanto o seu planejamento quanto a aplicação do modelo propriamente dito, impedindo que as competências sejam de fato mapeadas e corretamente captadas, girando o processo completamente e nutrindo o serviço público com servidores devidamente competentes para executar suas funções.

Sabe-se, todavia, que o desafio de implementar essas ações ainda é grande, principalmente quando se fala em atrelar pessoas à estratégia da organização. No entanto, o presente estudo evidencia um possível caminho a ser trilhado para que se possa conquistar mais um degrau nessa evolução rumo à gestão por competências. 


\section{PROCEDIMENTOS METODOLÓGICOS}

No presente estudo, a pesquisa foi aplicada, pois esta, segundo Vergara (2012) visa gerar conhecimentos para a aplicação prática e dirigidos à solução de problemas específicos, com uma finalidade prática. Com relação à abordagem, foi qualitativa, na medida em que evidencia uma relação dinâmica entre o mundo real e o sujeito, compreendendo que a subjetividade deste último não pode ser traduzida em números (SILVA; MENEZES, 2005), preocupando-se mais com o processo e não simplesmente com os resultados e o produto dela resultante (TRIVIÑOS, 2012).

Quanto aos seus fins, o presente estudo classificou-se como descritivo, já que objetivou descrever as características de uma determinada população e teve como finalidade identificar possíveis relações entre variáveis (GIL, 2002), sem o compromisso de explicar os fenômenos (VERGARA, 2012).

Em relação aos seus procedimentos técnicos, esta pesquisa caracterizou-se de quatro formas: bibliográfica, abrangeu bibliografia tornada pública em relação ao tema em estudo, permitindo ao pesquisador uma cobertura ampla de inúmeros fatos (GIL, 2002); documental, pois foi realizada em documentos conservados no interior de órgãos públicos ou privados de qualquer natureza (VERGARA, 2012); pesquisa de campo, fornecendo uma descrição ampla e profunda de algum fenômeno social e permite que os investigadores retenham as características holísticas e significativas dos eventos da vida real (YIN, 2010); e, estudo de caso, na medida em que correspondeu ao levantamento de dados no próprio local onde os fenômenos ocorrem ou que dispõe de elementos para explicá-lo (VERGARA, 2012).

Buscando delimitar o estudo com vistas ao alcance dos seus objetivos e considerando a atual estrutura da PRODEGESP, enfatizando o seu nível intermediário, tem-se como sujeitos de pesquisa a Pró-Reitora de Desenvolvimento e Gestão de Pessoas, ocupante de cargo de chefia com CD (cargo de direção) do tipo dois (CD-2), o Coordenador de Desenvolvimento e Gestão de Pessoas, ocupante de função gratificada do tipo 1 (FG-1), os diretores dos três departamentos da PRODEGESP (Departamento de Atenção à Saúde DAS, Departamento de Desenvolvimento de Pessoas - DDP e Departamento de Administração de Pessoal - DAP), ocupantes de cargos de chefia com CD do tipo quatro (CD-4), 05 (cinco) servidores ocupantes de cargos com funções gratificadas do tipo um (FG1), 06 (seis) servidores ocupantes de cargos com funções gratificadas do tipo três (FG-3) e 01 (um) servidor ocupante de cargo com função gratificada do tipo dois (FG-2), totalizando 17 pessoas. 
Neste estudo, optou-se por considerar como chefias de nível intermediário os 03 (três) diretores de departamento da PRODEGESP, ocupantes de CD-4, conforme apresentado na Figura 2.

Figura 2 - Organograma da PRODEGESP

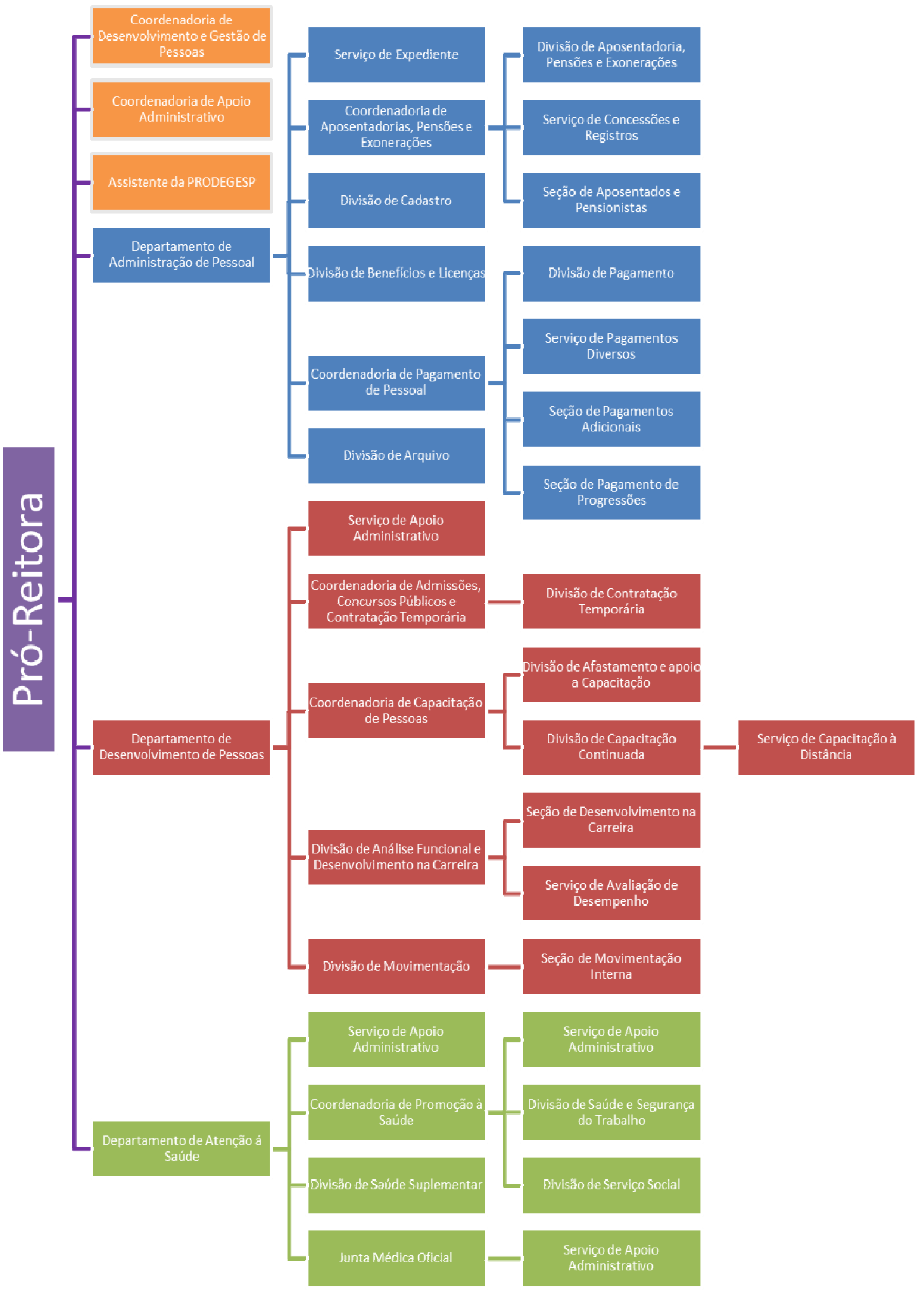

Fonte: UFSC (2017b). 
Entendendo que a participação dos sujeitos aqui pesquisados possui grande peso para a interpretação deste estudo, para a coleta de dados, além da pesquisa documental e bibliográfica, fez-se uso de observação, entrevistas semiestruturadas e questionário.

As cinco entrevistas realizadas com os dois dirigentes máximos e os três diretores da PRODEGESP visaram à compreensão das competências organizacionais da organização, das competências gerenciais requeridas aos gestores e daquelas que já são de seu domínio. Essas entrevistas foram realizadas de forma aberta, a partir da verbalização das definições expostas na teoria, com o intuito de obter do entrevistado a sua opinião acerca do tema. Por sua vez, as respostas obtidas com as entrevistas foram analisadas e, a partir do discurso dos entrevistados, foram inferidas as competências gerenciais requeridas ao cargo de diretor e existentes neste mesmo cargo, viabilizando a construção do segundo instrumento de coleta de dados, o questionário.

Além disso, cabe dizer que, uma vez listadas as competências requeridas aos cargos de nível intermediário da PRODEGESP e montado o questionário, este passou por um préteste, que foi aplicado a um grupo de 4 (quatro) pessoas diferentes.

No total, foram realizadas 5 (cinco) entrevistas e aplicados 17 (dezessete) questionários, tendo sido identificados os sujeitos entrevistados pelas letras E1, E2, E3, E4 e E5. O questionário foi composto por duas etapas, sendo a primeira responsável por medir o grau em que cada competência era requerida ao cargo analisado, sendo equiparada a uma "situação ideal"; a segunda etapa teve por objetivo medir o grau em que a mesma competência de fato existia nos ocupantes dos cargos de diretor de departamento, tendo sido apresentada como a "situação atual". Essa divisão do instrumento em duas etapas permitiu que fosse evidenciado o gap ou lacuna entre o nível de competência que ocupantes dos cargos precisam apresentar e o nível que efetivamente possuem.

A partir da demonstração desse gap, foram selecionadas as competências que basearam as ações de capacitação apresentadas no item 3.4 desta pesquisa. Os dados foram analisados por meio da estatística descritiva, com base na aplicação da Escala Likert de 5 pontos, conforme indicações apresentadas no Quadro 1. 
Quadro 1 - Classificação das competências no questionário de acordo com a etapa

\begin{tabular}{|c|c|c|c|c|}
\hline \multicolumn{5}{|c|}{$\begin{array}{c}\text { Etapa 1: } \\
\text { Grau em que a competência é requerida ao cargo de diretor }\end{array}$} \\
\hline 5 & 4 & 3 & 2 & 1 \\
\hline Muito Forte & Forte & Médio & Fraco & Muito Fraco \\
\hline $\begin{array}{l}\text { Atribua o grau } \\
5 \text { se você achar } \\
\text { que o cargo } \\
\text { requer um grau } \\
\text { MUITO } \\
\text { FORTE da } \\
\text { competência } \\
\text { investigada. }\end{array}$ & $\begin{array}{l}\text { Atribua o grau } 4 \\
\text { se você achar } \\
\text { que o cargo } \\
\text { requer um grau } \\
\text { FORTE da } \\
\text { competência } \\
\text { investigada. }\end{array}$ & $\begin{array}{c}\text { Atribua o } \\
\text { grau } 3 \text { se } \\
\text { você achar } \\
\text { que o cargo } \\
\text { requer um grau } \\
\text { MÉDIO } \\
\text { da competência } \\
\text { investigada. }\end{array}$ & $\begin{array}{c}\text { Atribua o } \\
\text { grau } 2 \text { se } \\
\text { você achar } \\
\text { que o cargo } \\
\text { requer um grau } \\
\text { FRACO } \\
\text { da competência } \\
\text { investigada. }\end{array}$ & $\begin{array}{c}\text { Atribua o grau } 1 \\
\text { se você achar } \\
\text { que o cargo } \\
\text { requer um grau } \\
\text { MUITO FRACO } \\
\text { da } \\
\text { competência } \\
\text { investigada. }\end{array}$ \\
\hline \multicolumn{5}{|c|}{$\begin{array}{l}\text { Etapa 2: } \\
\text { te no desempenho das atividades dos diretores }\end{array}$} \\
\hline 5 & 4 & 3 & 2 & 1 \\
\hline Muito Forte & Forte & Médio & Fraca & Muito Fraca \\
\hline $\begin{array}{l}\text { Atribua o grau } \\
5 \text { se você achar } \\
\text { que o diretor } \\
\text { apresenta um } \\
\text { grau } \\
\text { MUITO } \\
\text { FORTE da } \\
\text { competência } \\
\text { investigada. }\end{array}$ & $\begin{array}{c}\text { Atribua o grau } 4 \\
\text { se você achar } \\
\text { que o diretor } \\
\text { apresenta um } \\
\text { grau } \\
\text { FORTE da } \\
\text { competência } \\
\text { investigada. }\end{array}$ & $\begin{array}{c}\text { Atribua o } \\
\text { grau } 3 \text { se } \\
\text { você achar } \\
\text { que o diretor } \\
\text { apresenta um } \\
\text { grau } \\
\text { MÉDIO } \\
\text { da competência } \\
\text { investigada. }\end{array}$ & $\begin{array}{c}\text { Atribua o } \\
\text { grau } 2 \text { se } \\
\text { você achar } \\
\text { que o diretor } \\
\text { apresenta um } \\
\text { grau } \\
\text { FRACO } \\
\text { da competência } \\
\text { investigada }\end{array}$ & $\begin{array}{c}\text { Atribua o grau } 1 \\
\text { se você achar } \\
\text { que o diretor } \\
\text { apresenta um } \\
\text { grau } \\
\text { MUITO FRACO } \\
\text { da } \\
\text { competência } \\
\text { investigada. }\end{array}$ \\
\hline
\end{tabular}

Fonte: elaborado pelas autoras.

\section{APRESENTAÇÃO E DISCUSSÃO DOS RESULTADOS}

\subsection{A UFSC E A PRODEGESP}

A Universidade Federal de Santa Catarina (UFSC), com sede em Florianópolis/SC, foi fundada em 18 de dezembro de 1960 (RODRIGUES, 2010). Criada com o objetivo de promover o ensino, a pesquisa e a extensão, possui atualmente uma comunidade formada por cerca de 50 mil pessoas, entre docentes, técnico-administrativos e estudantes. Destes, aproximadamente 5.500 constituem-se em professores e técnicos, que atuam em atividades referência no Brasil e Exterior (UFSC, 2017a).

Com relação à sua estrutura, a UFSC conta atualmente com 7 Pró-Reitorias, 10 Secretarias e 11 Centros de Ensino, além de órgãos deliberativos e suplementares (UFSC, 
2017a). Este estudo tem como foco uma de suas Pró-Reitorias, mais especificamente a PróReitoria de Desenvolvimento e Gestão de Pessoas (PRODEGESP), instituída em 10/05/2016, sendo responsável por gestar os servidores técnico-administrativos e docentes da Universidade, tendo como principais metas: 1) a proposição de diretrizes a fim de possibilitar a implementação da gestão por competências na capacitação; 2) buscar meios para captar recursos financeiros objetivando o fortalecimento das ações de capacitação a distância promovidas pela PRODEGESP; 3) promover mecanismos de disseminação do conhecimento obtido em ações de capacitação entre os servidores (UFSC, 2015).

Além disso, segundo o PDI 2015-2019 (UFSC, 2015, p. 78), vê-se que a capacitação dos servidores é compreendida como um ponto importante na gestão de pessoas, manifestando-se como um "processo permanente e deliberado de aprendizagem, que utiliza ações de aperfeiçoamento e qualificação com o propósito de contribuir para o desenvolvimento de competências institucionais por meio do desenvolvimento de competências individuais". Este objetivo é ratificado pela fala de um de seus gestores, aqui identificado como E1, que afirma ser a PRODEGESP:

[...] responsável pelo processo da gestão de pessoas da instituição, $e$ o faz por meio de 3 grandes áreas que nós compreendemos que podemos fazer o processo da gestão de pessoas, que são: a área do desenvolvimento, que abrange todo o desenvolvimento do servidor na carreira, incluindo o seu bem estar; a área de administração de pessoas, que abrange toda a área administrativa, mais cartorial do desenvolvimento da carreira do servidor, e a área de atenção à saúde, que também dá sustentação pro desenvolvimento e pra área administrativa.

Enquanto parte integrante da Administração Pública Federal, ao buscar inserir um modelo de gestão baseado em competências nas suas práticas, a PRODEGESP caminha ao encontro do que aponta a legislação balizadora de suas atividades e também do que defendem os teóricos estudados, já que volta seus esforços para o planejamento, captação, desenvolvimento e avaliação das competências necessárias à consecução de seus objetivos.

\subsection{COMPETÊNCIAS ORGANIZACIONAIS DA PRODEGESP}

Neste trabalho, definiu-se a PRODEGESP como a organização a ser pesquisada e, consequentemente, as competências aqui levantadas são as suas competências enquanto 
organização. Essas competências foram extraídas de duas entrevistas realizadas com os dois dirigentes máximos da Pró-Reitoria e serviram de baliza para a definição das competências gerenciais dos seus diretores. O Quadro 2 apresenta as três principais competências organizacionais da PRODEGESP, inferidas a partir dos discursos dos entrevistados e agrupadas por similaridade de significado, apresentadas conforme proposto por Brandão e Bahry (2005).

\section{Quadro 2 - Competências organizacionais}

\begin{tabular}{|c|c|}
\hline $\begin{array}{l}\text { COMPORTAMENTO } \\
\text { (verbo + objeto da ação) }\end{array}$ & CRITÉRIO e CONDIÇÃO \\
\hline $\begin{array}{l}\text { 1. Conhecer tecnicamente a área } \\
\text { de gestão e de gestão de pessoas }\end{array}$ & $\begin{array}{c}\text { Sabendo aplicar suas legislações de maneira ágil, confiável e } \\
\text { transparente }\end{array}$ \\
\hline $\begin{array}{l}\text { 2. Querer lidar com pessoas e } \\
\text { trabalhar junto delas }\end{array}$ & $\begin{array}{c}\text { Compreendendo e respeitando a individualidade e a história de } \\
\text { cada servidor, buscando adequar os procedimentos e as } \\
\text { atividades ao contexto vivido }\end{array}$ \\
\hline $\begin{array}{c}\text { 3. Potencializar o } \\
\text { desenvolvimento dos servidores }\end{array}$ & Por meio da capacitação \\
\hline
\end{tabular}

Fonte: Adaptado de Brandão e Bahry (2005).

A primeira competência listada no Quadro 2 pode ser encontrada na fala dos gestores entrevistados, a exemplo do que diz E1, quando afirma que

[...] que nós temos legislações que nos limitam, mas nós temos também habilidades para verificar a ampliação dessas legislações na prática [...] essa habilidade é querer trabalhar com as pessoas, saber que cada dificuldade é uma dificuldade de uma pessoa que tem uma história nessa instituição, que tem uma história e que o nosso papel é fazer com que ele tenha uma vida institucional mais tranquila, mais realizada, potencializada dentro da casa.

Fleury e Fleury (2004) mantêm o mesmo entendimento quando sinalizam as competências organizacionais como as competências coletivas associadas as atividades-meio e às atividades-fim da organização. Ou seja, a teoria aqui pesquisada fortalece a noção que os gestores têm acerca do papel da PRODEGESP, como pode ser observado na fala do E2:

Nós cuidamos aqui da vida funcional das pessoas, em todas as suas etapas, desde a admissão até a sua aposentadoria, então a gente precisa dessa habilidade de lidar com o ser humano e também da atitude de estar aberto pra isso, sabendo que as pessoas são muito diferentes e precisam ser respeitadas. 
A segunda competência organizacional relacionada, que traz o aspecto comportamental de querer trabalhar naquele contexto, pode ser visualizada no discurso do E1, ao dizer que ter essa predisposição de lidar com pessoas é:

[...] difícil assim, no dia a dia, porque nós trabalhamos com o uma área muito burocratizada, e nós temos, lamentavelmente, e isso me entristece muito, uma noção de que nós não funcionamos, né, tudo que nós fizemos, tudo é muito burocrático, por que? Porque por trás da área de gestão de pessoas tem algo chamado Ministério do Planejamento, tem algo chamado MEC, que têm políticas públicas que engessam muitas vezes as nossas ações, então por isso que nós precisamos ir além desse conhecimento, dessa habilidade, e ter atitude no potencializar o servidor nessa instituição, essa é a nossa grande meta.

E2 ratifica essa ideia quando afirma que:

[...] como atitude, de trabalhar com pessoas, é a atitude de estar predisposto a lidar com pessoas, que é diferente de lidar simplesmente com papéis, diferente, por exemplo, de se trabalhar só com, sei lá, eu imagino, um departamento que seja mais cartorial, que trabalhe só com processo, que aquilo vai gerar um produto [...].

A terceira competência pode ser claramente relacionada ao destaque de Ruas (2005), quando traz a ligação entre a competência organizacional e aos elementos da estratégia da organização (missão, visão e intenção estratégica).

\subsection{COMPETÊNCIAS GERENCIAIS REQUERIDAS E EXISTENTES}

As competências gerenciais foram obtidas por meio da análise do discurso de 5 (cinco) gestores de gestão de pessoas da PRODEGESP, dentre eles os próprios ocupantes dos cargos aqui analisados. Com relação às competências levantadas com as entrevistas, alguns elementos que constituem as competências gerenciais, apontados por Pelissari, Gonzalez e Vanalle (2011), foram encontrados nas falas dos gestores e essa correlação está apresentada no Quadro 3. 


\section{Quadro 3 - Elementos da competência gerencial: teoria $x$ prática}

\begin{tabular}{|c|c|}
\hline $\begin{array}{c}\text { Elementos da Competência } \\
\text { Gerencial } \\
\text { (enfoque teórico) }\end{array}$ & $\begin{array}{c}\text { Elementos da Competência Gerencial } \\
\text { (entrevistas) }\end{array}$ \\
\hline $\begin{array}{l}\text { Inteligência: bom nível intelectual } \\
\text { aliado à praticidade e ao bom senso; }\end{array}$ & $\begin{array}{l}\text { - conhecer as técnicas de gestão } \\
\text { (planejamento, organização, direção, controle, avaliação) } \\
\text { - ter conhecimento técnico da área de gestão de pessoas } \\
\text { - ter conhecimento técnico referente às áreas do } \\
\text { departamento }\end{array}$ \\
\hline $\begin{array}{l}\text { Estabilidade: capacidade emocional de } \\
\text { suportar pressões }\end{array}$ & - conhecer suas próprias limitações \\
\hline $\begin{array}{l}\text { Visão sistêmica da organização: } \\
\text { percepção da organização como um } \\
\text { todo, evitando decisões que favoreçam } \\
\text { apenas um determinado departamento } \\
\text { ou função; }\end{array}$ & $\begin{array}{l}\text { - entender a interligação entre os departamentos } \\
\text { - saber os efeitos que as ações do seu departamento têm } \\
\text { sobre os demais departamentos da PRODEGESP e da } \\
\text { UFSC } \\
\text { - compreender a UFSC como um todo (setores } \\
\text { interligados) } \\
\text { - ser o ponto de ligação entre a Pró-Reitora e demais } \\
\text { servidores } \\
\text { - ter interlocução política com os outros segmentos da } \\
\text { UFSC (técnicos, docentes e discentes) }\end{array}$ \\
\hline $\begin{array}{l}\text { Capacidade para organizar e } \\
\text { solucionar: situações problemáticas } \\
\text { exigem soluções, pois existem } \\
\text { situações em que é necessário tomar } \\
\text { decisões apesar de dispor de pouca ou } \\
\text { nenhuma informação; }\end{array}$ & $\begin{array}{l}\text { - envolver as equipes nos processos, nas decisões } \\
\text { - estimular a criatividade entre os seus servidores } \\
\text { - criar um ambiente de trabalho saudável, propício ao } \\
\text { desenvolvimento } \\
\text { - criar condições favoráveis (estrutura, clima, materiais) } \\
\text { para que as equipes técnicas realizem os seus trabalhos }\end{array}$ \\
\hline $\begin{array}{l}\text { Percepção quanto à satisfação de sua } \\
\text { equipe de trabalho: a auto-realização é } \\
\text { uma das causas da satisfação no } \\
\text { trabalho; }\end{array}$ & $\begin{array}{l}\text { - saber lidar com pessoas } \\
\text { - saber ouvir (respeitar a opinião do outro) } \\
\text { - saber acolher (ser receptivo) } \\
\text { - respeitar as diversidades das pessoas } \\
\text { - ter sensibilidade } \\
\text { - conhecer a sua equipe de trabalho, sua história, seus } \\
\text { anseios e preocupações }\end{array}$ \\
\hline
\end{tabular}

Fonte: adaptado de Pelissari, Gonzalez e Vanalle (2011).

Em um segundo momento, foi perguntado quais eram as competências gerenciais que os diretores de departamento possuíam; os cinco gestores arguidos responderam que as competências existentes seriam as mesmas que as requeridas, apresentando variações apenas no grau em que cada uma era exigida dele e de fato existia no diretor. Entretanto, alguns entrevistados salientam que o lado político existente na seleção dos gestores pode conflitar com a capacidade técnica e pessoal a ser analisada quando da nomeação dos diretores, fato que pode ser observado no discurso de E5, quando diz: 
A indicação dos cargos gerenciais nessa Universidade é feita de forma política, tá? Independente de pré-requisito, ou não, é feita de forma política.. .sempre foi assim. Agora vamos pensar? É o ideal? Em alguns casos sim, outros não. Tem que ter uma mescla, entre o político com a competência técnica para exercer aquela atividade...não adianta a pessoa ter um trânsito político reconhecido dentro da Universidade sem ter a devida competência para gestar uma equipe de trabalho. (...) tem que ser levado em conta a formação acadêmica da pessoa, o seu histórico de trabalho e também do seu envolvimento político (...) então é um conjunto disso tudo).

Assim, após serem mapeadas e agrupadas dentro de suas respectivas categorias, o instrumento de coleta foi então dividido em duas etapas (competências requeridas $\mathrm{x}$ existentes). Isso possibilitou estabelecer o gap entre o que lhes é exigido e o que eles oferecem enquanto gestores. Em ambas as etapas, para a tabulação dos dados, os valores atribuídos a cada competência foram transferidos para uma planilha de linhas e colunas, onde as linhas representaram as competências e, nas colunas, foram dispostos os sujeitos e os graus atribuídos pelos respondentes. Para cada linha foi calculada a média aritmética do respectivo grau, recebendo destaque as competências de cada categoria que apresentaram média igual ou superior a 4,5 na primeira etapa e média igual ou inferior a 3,49 na segunda.

Na primeira etapa, cabe ressaltar que das 48 competências inferidas e relacionadas para avaliação, apenas uma ("conhecer a história da UFSC e da PRODEGESP”) recebeu o grau médio 3 como avaliação, ou seja, todas as demais foram avaliadas como sendo fortemente ou muito fortemente requeridas ao cargo de diretor de departamento, o que valida as informações inferidas das entrevistas, que resultaram nas competências listadas no instrumento de coleta. Diante destes resultados, percebe-se que, de uma maneira geral, as competências inferidas das entrevistas possuem grande exigência das chefias intermediárias.

A exemplo do que ocorreu na primeira fase da tabulação, na segunda etapa, os valores atribuídos a cada competência foram novamente transferidos para uma planilha de linhas e colunas; para cada linha foi calculada a média aritmética do respectivo grau, recebendo destaque as competências de cada categoria que apresentaram média igual ou inferior a 3,49.

Das 48 competências inferidas e relacionadas para avaliação, 17 receberam média igual ou inferior a 3,49 como avaliação, sendo consideradas, desta forma, presentes em nível médio ou fraco. Destaca-se, ainda, que nenhuma das competências avaliadas foi considerada como muito fraca (grau 1) dentre os diretores. Ao se comparar as duas etapas, pode-se 
observar o gap entre as competências, evidenciando as que mais carecem de capacitação, objetivo final deste estudo (Tabela 1).

Tabela 1 - Competências requeridas e existentes

\begin{tabular}{|c|c|c|c|}
\hline & COMPETÊNCIA & $\begin{array}{l}\text { GRAU QUE É } \\
\text { REQUERIDA }\end{array}$ & $\begin{array}{l}\text { GRAU QUE } \\
\text { EXISTE }\end{array}$ \\
\hline 1 & conhecer suas próprias limitações & 4,18 & 3,94 \\
\hline 2 & saber lidar com pessoas & 4,88 & 4,12 \\
\hline 3 & $\begin{array}{l}\text { saber ouvir (respeitar a opinião do outro, } \\
\text { sem impor a sua) }\end{array}$ & 4,71 & 4,18 \\
\hline 4 & saber acolher (ser receptivo) & 4,76 & 4,47 \\
\hline 5 & aprender com as mudanças & 4,53 & 3,63 \\
\hline 6 & respeitar as diversidades das pessoas & 4,47 & 4,41 \\
\hline 7 & ter sensibilidade & 4,50 & 4,00 \\
\hline 8 & estar presente & 4,18 & 4,13 \\
\hline 9 & procurar desenvolver-se por meio da capacitação & 4,12 & 3,31 \\
\hline 10 & $\begin{array}{l}\text { conhecer as técnicas de gestão } \\
\text { (planejamento, organização, direção, controle, avaliação) }\end{array}$ & 4,47 & 3,65 \\
\hline 11 & ter conhecimento técnico da área de gestão de pessoas & 4,29 & 4,00 \\
\hline 12 & ter conhecimento técnico referente às áreas do departamento & 4,12 & 4,06 \\
\hline 13 & conhecer os sistemas operacionais da PRODEGESP & 3,82 & 4,24 \\
\hline 14 & saber operacionalizar as legislações de gestão de pessoas & 4,31 & 4,12 \\
\hline 15 & conhecer a história da UFSC e da PRODEGESP & 3,41 & 4,24 \\
\hline 16 & conhecer os princípios, objetivos e metas da PRODEGESP & 4,53 & 4,24 \\
\hline 17 & $\begin{array}{l}\text { conhecer a sua equipe de trabalho, sua história, seus anseios } \\
\text { e preocupações }\end{array}$ & 4,71 & 4,00 \\
\hline 18 & conhecer o trabalho desenvolvido por seus servidores & 4,65 & 4,06 \\
\hline 19 & entender a interligação entre os departamentos & 4,53 & 4,06 \\
\hline 20 & $\begin{array}{l}\text { saber os efeitos que as ações do seu departamento têm sobre } \\
\text { os demais departamentos da PRODEGESP e da UFSC }\end{array}$ & 4,76 & 4,06 \\
\hline 21 & compreender a UFSC como um todo (setores interligados) & 4,29 & 3,94 \\
\hline 22 & saber gestar a equipe integralmente & 4,88 & 3,38 \\
\hline 23 & envolver as equipes nos processos, nas decisões & 4,69 & 3,47 \\
\hline 24 & possibilitar o desenvolvimento dos seus servidores & 4,59 & 4,06 \\
\hline 25 & $\begin{array}{l}\text { posicionar-se enquanto gestor da PRODEGESP e da } \\
\text { Universidade (e não só do seu departamento) }\end{array}$ & 4,29 & 3,41 \\
\hline 26 & saber cobrar o melhor resultado das equipes & 4,29 & 3,35 \\
\hline 27 & gestar com as pessoas (e não as pessoas) & 4,41 & 3,47 \\
\hline 28 & agregar as pessoas & 4,67 & 3,56 \\
\hline 29 & buscar ver o outro com empatia & 4,53 & 3,94 \\
\hline 30 & estar aberto a compreender as pessoas & 4,53 & 4,18 \\
\hline 31 & ser líder & 4,65 & 3,18 \\
\hline 32 & ter a sua liderança reconhecida pelos seus servidores & 4,18 & 3,12 \\
\hline & ser um gestor coletivo e colaborativo & 4,71 & 3,53 \\
\hline
\end{tabular}




\begin{tabular}{ll|c|c}
\hline 34 & ser capaz de potencializar a sua equipe de trabalho & 4,65 & 3,53 \\
\hline 35 & ganhar a confiança das pessoas & 4,65 & 3,82 \\
\hline 36 & estimular a criatividade entre os seus servidores & 4,41 & 3,18 \\
\hline 37 & $\begin{array}{l}\text { criar um ambiente de trabalho saudável, propício ao } \\
\text { desenvolvimento }\end{array}$ & 4,82 & 3,82 \\
\hline 38 & $\begin{array}{l}\text { criar condições favoráveis (estrutura, clima, materiais) para } \\
\text { que as equipes técnicas realizem os seus trabalhos }\end{array}$ & 4,71 & 3,12 \\
\hline 39 & buscar a motivação das equipes & 4,53 & 3,24 \\
\hline 40 & buscar o melhor resultado & 4,53 & 3,59 \\
\hline 41 & $\begin{array}{l}\text { amenizar ruídos e facilitar a comunicação entre os níveis } \\
\text { organizacionais }\end{array}$ & 4,47 & 3,12 \\
\hline 42 & saber dialogar com suas equipes & 4,82 & 3,65 \\
\hline 43 & saber incentivar o diálogo entre as equipes & 4,65 & 3,35 \\
\hline 44 & $\begin{array}{l}\text { ser o ponto de ligação entre a Pró-Reitora e demais } \\
\text { servidores }\end{array}$ & 4,41 & 3,41 \\
\hline 45 & $\begin{array}{l}\text { interlocução política com os outros segmentos da UFSC } \\
\text { (técnicos, docentes e discentes) }\end{array}$ & 4,12 & 3,24 \\
\hline 46 & $\begin{array}{l}\text { demonstrar a importância das atividades desenvolvidas pelas } \\
\text { equipes }\end{array}$ & 4,76 & 3,65 \\
\hline 47 & compartilhar os objetivos organizacionais & 4,35 & 3,65 \\
\hline 48 & saber comunicar-se & 4,71 & 3,76 \\
\hline \hline
\end{tabular}

Fonte: elaborada pelas autoras.

Para fins de melhor estruturar as ações de capacitação propostas neste trabalho, no Quadro 5, pode ser visualizado o gap (ou lacuna) entre as competências mais requeridas e o grau em que de fato elas existem nos gestores estudados. Quanto maior a lacuna existente entre o grau em que determinada competência é requerida ao cargo e sua efetiva presença no desempenho dos servidores, maior deverá ser o empenho da organização em desenvolvê-la, já que ela se faz muito exigida, porém pouco existente. A Tabela 2 ( na página seguinte) destaca as competências que receberam ênfase para a construção as ações de capacitação propostas.

Segundo Amaral (2006), o aperfeiçoamento permanente de servidores poderá contribuir para a melhoria do nível de qualidade do serviço público. Justamente por isso, a autora (2006) sugere que se deve olhar, com atenção especial, para o fator crítico à sua melhoria: o servidor público e sua capacitação constante. Este processo de capacitação vem ao encontro do desenvolvimento das competências, fase crítica do modelo aqui apresentado, uma vez que visa melhorar o desempenho dos profissionais e/ou da organização. Leal (2015) ratifica essa ideia quando afirma que as competências requeridas a determinado cargo, seja ele enquadrado na iniciativa privada ou no serviço público, são passíveis de serem desenvolvidas ou aperfeiçoadas por meio de treinamento, desenvolvimento e educação. 
Tabela 2 - Gap entre competências requeridas e existentes

\begin{tabular}{|c|c|c|c|c|}
\hline CATEGORIA & COMPETÊNCIAS & $\begin{array}{c}\text { GRAU } \\
\text { QUE É } \\
\text { REQUERIDA }\end{array}$ & $\begin{array}{c}\text { GRAU } \\
\text { QUE SE } \\
\text { APRESENTA }\end{array}$ & GAP \\
\hline $\begin{array}{l}\text { Competências } \\
\text { Pessoais }\end{array}$ & $\begin{array}{l}\text { procurar desenvolver-se por meio } \\
\text { da capacitação }\end{array}$ & 4 & 3 & 1 \\
\hline $\begin{array}{l}\text { Competências de } \\
\text { Gestão - } \\
\text { Integração }\end{array}$ & saber gestar a equipe integralmente & 5 & 3 & 2 \\
\hline $\begin{array}{l}\text { Competências de } \\
\text { Gestão - } \\
\text { Relacionamento }\end{array}$ & $\begin{array}{c}\text { saber cobrar o melhor resultado das } \\
\text { equipes }\end{array}$ & 4 & 3 & 1 \\
\hline \multirow{3}{*}{$\begin{array}{l}\text { Competências de } \\
\text { Gestão - } \\
\text { Liderança }\end{array}$} & $\begin{array}{c}\text { criar um ambiente de trabalho } \\
\text { saudável, propício ao } \\
\text { desenvolvimento }\end{array}$ & 5 & 3 & 2 \\
\hline & $\begin{array}{c}\text { ter a sua liderança reconhecida } \\
\text { pelos seus servidores }\end{array}$ & 4 & 3 & 1 \\
\hline & $\begin{array}{c}\text { criar condições favoráveis } \\
\text { (estrutura, clima, materiais) para } \\
\text { que as equipes técnicas realizem os } \\
\text { seus trabalhos }\end{array}$ & 5 & 3 & 2 \\
\hline $\begin{array}{l}\text { Competências de } \\
\text { Gestão - } \\
\text { Comunicação }\end{array}$ & $\begin{array}{c}\text { amenizar ruídos e facilitar a } \\
\text { comunicação entre os níveis } \\
\text { organizacionais }\end{array}$ & 4 & 3 & 1 \\
\hline
\end{tabular}

Fonte: elaborada pelas autoras.

Embora pouco conhecida no setor público, a gestão por competências tira o foco da atribuição formal de um posto de trabalho; as competências são constatadas quando utilizadas em situação profissional, a partir da qual são passíveis de validação. Assim, "cada órgão público deve passar a identificá-las, avaliá-las, validá-las e fazê-las evoluir" (AMARAL, 2006, p. 554). Muito embora haja uma dificuldade maior de aplicação no serviço público, a capacitação profissional e o consequente desenvolvimento de competências, possibilita a visualização das competências básicas individuais e institucionais, atuando no sentido de que todos os participantes tenham as qualificações necessárias para sustentar os objetivos, as oportunidades e os desafios da Instituição. 


\subsection{AÇÕES DE CAPACITAÇÃO PARA O DESENVOLVIMENTO DE COMPETÊNCIAS}

Segundo Amaral (2006), o aperfeiçoamento permanente de servidores poderá contribuir para a melhoria da qualidade do serviço público. Essa relevância pode ser percebida também na fala dos gestores entrevistados.

Toda capacitação é fundamental. Então eu acredito que a busca constante pelo aprendizado sempre deve ocorrer. Ninguém tem a noção de tudo (...) a gente sempre precisa aprender. Então os diretores precisam estar em constante aprendizado em virtude de que as nossas legislações estão sempre em mudança, o cenário muda. Então a gente precisa estar se adaptando a essas questões. Então é válida a capacitação. Não sei se a capacitação dos diretores precisa chegar tanto no operacional, lá na ponta; mas uma capacitação muito mais no nível macro, estratégico, das atividades que são feitas, seria fundamental para os diretores (E3).

[...] a atualização constante se faz bastante necessária. E ver o que tem de novidade na área de gestão de pessoas, das técnicas mesmo, porque sempre tem coisa nova surgindo ali que dá para melhorar. Então a capacitação, sim, sempre vai poder desenvolver o gestor $e$ todo mundo na verdade, né? E também pode desenvolver(..) .as capacitações mais comportamentais, né, podem ajudar bastante a desenvolver a empatia, a desenvolver as técnicas de acolhimento, recepção, atendimento. Então a capacitação é um foco muito importante (E2).

Leal (2015) ratifica essa ideia quando afirma que as competências requeridas a determinado cargo são passíveis de desenvolvimento por meio de treinamento e educação. Em sua aplicação no serviço público, o desenvolvimento de competências é expresso no inciso I, do artigo $2^{\circ}$. do Decreto $n^{\circ}$. 5.707/2006, que define a capacitação como um processo permanente e deliberado de aprendizagem, com o propósito de contribuir para o desenvolvimento de competências (BRASIL, 2006).

Diante disso, nesta pesquisa, objetiva-se estruturar ações de capacitação para as competências requeridas ao cargo de diretor de departamento PRODEGESP. Contudo, antes da efetiva proposição dessas ações, é importante trazer à discussão a forma com que ocorrem as capacitações na UFSC. 
A UFSC promove suas capacitações por meio da sua Coordenadoria de Capacitação de Pessoas (CCP), do seu Departamento de Desenvolvimento de Pessoas (DDP). Atualmente, a CCP é responsável por coordenar, planejar, executar e avaliar as ações de capacitação na UFSC (UFSC, 2017c). Todos os anos, a CCP elabora o Plano Anual de Capacitação (PAC), ferramenta instituída pelo Decreto $\mathrm{n}^{\circ}$ 5.707/2006 (PNDP), sendo um dos instrumentos da Política de Capacitação e Desenvolvimento dos servidores da UFSC. O PAC/UFSC destinase a proporcionar os meios para a operacionalização das diretrizes que norteiam o processo de desenvolvimento profissional dos servidores da Universidade (UFSC, 2015).

Nesta pesquisa, a partir do rol de competências apresentado no Quadro 5 - Gap entre Competências Requeridas e Existentes, e as ações de capacitação presentes no PAC/UFSC, percebeu-se a ausência de ações de capacitação que pudessem suprir totalmente as competências apresentadas. Desta forma, foram buscadas ações de capacitação oferecidas por outras instituições de ensino brasileiras, cujos planos anuais de capacitação estavam disponíveis para consulta on line (IFSC, 2016; UNB, 2017; UFBA, 2016). Muito embora esses cursos não sejam abertos aos servidores da UFSC, eles servem de exemplo para a sua possível criação, a fim de proporcionar aos diretores a possibilidade de capacitação.

A busca por ações de capacitação estendeu-se também à Escola Nacional de Administração Pública (ENAP), uma escola de governo do Poder Executivo Federal, que oferece formação e aperfeiçoamento em Administração Pública a servidores públicos federais (ENAP, 2017). Essa análise resultou na proposta de ações de capacitação, apresentada no Quadro 4.

\section{Quadro 4 - Proposta de Plano de Capacitação para os Diretores da PRODEGESP}

\begin{tabular}{|c|c|}
\hline \multicolumn{2}{|c|}{$\begin{array}{c}\text { COMPETÊNCIA 1: } \\
\text { "procurar desenvolver-se por meio da capacitação" }\end{array}$} \\
\hline $\begin{array}{l}\text { Ações de Capacitação Correlatas - } \\
\text { PAC/UFSC: } \\
\text { 1. Informações sobre: } \\
\text { - Concessão à Licença-Capacitação }\end{array}$ & $\begin{array}{l}\text { Ações de Capacitação Correlatas - } \\
\text { Outras Instituições : } \\
\text { 2. Curso de Formação de Gestores na área de } \\
\text { Educação - PAC/IFSC }\end{array}$ \\
\hline - Concessão de Afastamento de Curta & 3. Curso de Ética e Postura Profissional no Trabalho \\
\hline $\begin{array}{l}\text { - Apoio Financeiro as ações de } \\
\text { aperfeiçoamento }\end{array}$ & $\begin{array}{l}\text { 4. Curso de Análise e Melhoria de Processos - } \\
\text { PAC/UNB }\end{array}$ \\
\hline - Apoio Financeiro à Especialização & 5. Curso de Gerenciamento de Projetos (Níveis \\
\hline - Concessão de Afastamento Longa Duração & írio) - PAC/UNB \\
\hline $\begin{array}{c}\text { - Concessão de Horário Especial para } \\
\text { Servidor Estudante }\end{array}$ & $\begin{array}{l}\text { 6. Curso de Comunicação Gerencial - PAC/UNB } \\
\text { 7. Workshop de Gestão do Desempenho - }\end{array}$ \\
\hline
\end{tabular}




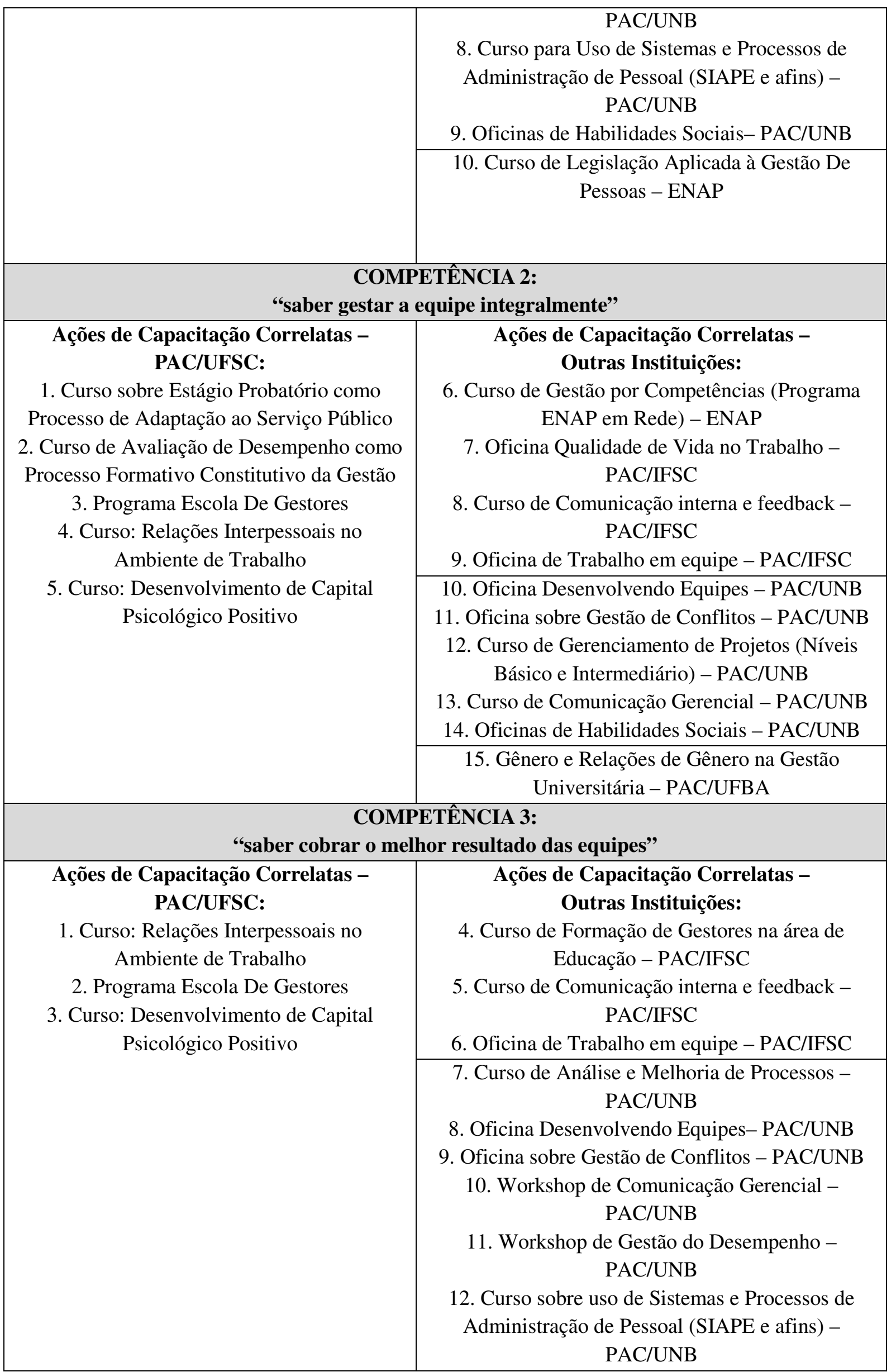




\begin{tabular}{|c|c|}
\hline & 13. Oficinas de Habilidades Sociais - PAC/UNB \\
\hline \multicolumn{2}{|c|}{$\begin{array}{l}\text { COMPETÊNCIA 4: } \\
\text { "criar um ambiente de trabalho saudável, propício ao desenvolvimento" }\end{array}$} \\
\hline \multirow{13}{*}{$\begin{array}{l}\text { Ações de Capacitação Correlatas - } \\
\text { PAC/UFSC: } \\
\text { 1. Curso: Relações Interpessoais no } \\
\text { Ambiente de Trabalho } \\
\text { 2. Curso: Desenvolvimento de Capital } \\
\text { Psicológico Positivo } \\
\text { 3. Curso: Educação Ambiental no Âmbito } \\
\text { Organizacional }\end{array}$} & Ações de Capacitação Correlatas - \\
\hline & Outras Instituições: \\
\hline & 4. Oficina Qualidade de Vida no Trabalho - \\
\hline & PAC/IFSC \\
\hline & $\begin{array}{l}\text { 5. Curso de Formação de Gestores na área de } \\
\text { Educacão - PAC/IFSC }\end{array}$ \\
\hline & 6. Oficina de Trabalho em equipe - PAC/IFSC \\
\hline & $\begin{array}{l}\text { 7. Curso de Análise e Melhoria de Processos - } \\
\text { PAC/UNB }\end{array}$ \\
\hline & 8. Oficina Desenvolvendo Equipes - PAC/UNB \\
\hline & $\begin{array}{l}\text { 9. Oficina sobre Gestão de Conflitos - PAC/UNB } \\
\text { 10. Curso de Gerenciamento de Proietos (Níveis }\end{array}$ \\
\hline & Básico e Intermediário) - PAC/UNB \\
\hline & $\begin{array}{l}\text { 11. Workshop de Comunicação Gerencial - } \\
\text { PAC/UNB }\end{array}$ \\
\hline & 12. Oficinas de Habilidades Sociais - PAC/UNB \\
\hline & $\begin{array}{l}\text { 13. Curso de Introdução à Saúde, Segurança e } \\
\text { Higiene Ocupacional - PAC/UFBA }\end{array}$ \\
\hline \multicolumn{2}{|c|}{ COMPETÊNCIA 5: } \\
\hline \multirow{7}{*}{$\begin{array}{l}\text { Ações de Capacitação Correlatas - } \\
\text { PAC/UFSC: } \\
\text { (não foram relacionadas ações) }\end{array}$} & $\begin{array}{c}\text { Ações de Capacitação Correlatas - } \\
\text { Outras Instituições: }\end{array}$ \\
\hline & $\begin{array}{l}\text { 1. Curso de Capacitação e Aperfeiçoamento em } \\
\text { Gestão e Liderança - PAC/IFSC }\end{array}$ \\
\hline & $\begin{array}{l}\text { 2. Curso de Formação de Gestores na área de } \\
\text { Educacão - PAC/IFSC }\end{array}$ \\
\hline & $\begin{array}{l}\text { 3. Curso de Comunicação interna e feedback - } \\
\text { PAC/IFSC }\end{array}$ \\
\hline & 4. Oficina de Trabalho em equipe - PAC/IFSC \\
\hline & $\begin{array}{l}\text { 5. Oficina sobre Gestão de Conflitos - PAC/UNB } \\
\text { 6. Workshop de Comunicação Gerencial - } \\
\text { PAC/UNB }\end{array}$ \\
\hline & $\begin{array}{l}\text { 7. Workshop de Gestão do Desempenho - } \\
\text { PAC/UNB }\end{array}$ \\
\hline \multicolumn{2}{|c|}{$\begin{array}{c}\text { COMPETÊNCIA 6: } \\
\text { “criar condições favoráveis (estrutura, clima, materiais) para que as } \\
\text { equipes técnicas realizem os seus trabalhos" }\end{array}$} \\
\hline $\begin{array}{c}\text { Ações de Capacitação Correlatas - } \\
\text { PAC/UFSC: }\end{array}$ & $\begin{array}{l}\text { Ações de Capacitação Correlatas - } \\
\text { Outras Instituicões. }\end{array}$ \\
\hline 1. Programa Escola De Gestores & 2. Oficina Oualidade de Vida no Trabalho - \\
\hline & PAC/IFSC \\
\hline & 3. Curso de Formação de Gestores na área de \\
\hline & $\begin{array}{l}\text { Educação - PAC/IFSC } \\
\text { 4. Oficina de Trabalho em equipe - PAC/IFSC }\end{array}$ \\
\hline & 5. Curso sobre Responsabilidade Sócio-Ambiental- \\
\hline
\end{tabular}




\begin{tabular}{|c|c|}
\hline \multirow{2}{*}{} & PAC/IFSC \\
\cline { 2 - 2 } & 6. Curso de Análise e Melhoria de Processos - \\
PAC/UNB
\end{tabular}

Fonte: elaborado pelas autoras.

Ainda sobre essa temática, neste momento, faz-se importante ressaltar a necessidade de capacitação indicada por E1, nas afirmações que seguem.

[...] uma capacitação mais formal, muitas vezes eu sinto que se faz. necessária. Mas, nesse primeiro momento, ela não é viável a todos os diretores. Então o que eu coloco pra eles: eles participam de fóruns nacionais, encontros de dirigentes eles participam, sempre que possível, eles fazem interlocuções com outras unidades para também trocarem experiências, mas por exemplo, nenhum dos 3 têm mestrado na área de gestão universitária. Eu acho fundamental. Eu colocaria 
como muito importante sim. Estamos inaugurando a escola de gestores, ação que vem com a capacitação, e com o Instituto de Gestão Latino-Americano Universitário - IGLU, um dos diretores irá fazer o curso ano que vem. Então assim, a capacitação formal é fundamental, no meu entendimento.

Ainda sobre a relevância do plano de capacitação, cabe transcrever as palavras de um dos gestores que respondeu ao questionário, aqui identificado como S7.

[...]o cargo de direção é de suma importância na PRODEGESP, tendo em vista ser o canal de conexão entre a Pró-Reitora e os demais setores. $O$ diretor deve ter conhecimento técnico de pessoal, gestão e relacionamento, assim como deve saber liderar, motivar e criar condições favoráveis para a equipe. As competências relacionadas aqui são relevantes e o ideal seria o perfil de servidor que apresentasse todas essas características. Para isso, a capacitação e demais ações de desenvolvimento são necessárias.

\section{CONSIDERAÇÕES FINAIS E RECOMENDAÇÕES}

Ao final deste trabalho, antes de resgatar efetivamente os objetivos inicialmente estabelecidos, propõe-se uma reflexão sobre o papel das pessoas nas organizações e o quanto a sua valorização e desenvolvimento podem aproximá-las do atingimento de suas metas e objetivos. Neste estudo, o ambiente organizacional analisado foi o de uma Universidade, a UFSC, mais especificamente a sua Pró-Reitoria de Desenvolvimento e Gestão de Pessoas (PRODEGESP), local dotado de estruturas e funcionalidades também complexas, multifacetadas, composto por sujeitos de diferentes perfis, trabalhando com a grande e principal missão de formar pessoas para o exercício profissional em sociedade.

Isto posto, ao evidenciar a íntima relação entre o desenvolvimento das pessoas e o atingimento de metas organizacionais, vê-se conexão com a análise realizada nesta pesquisa, que teve como pergunta de pesquisa como desenvolver as competências gerenciais das chefias intermediárias da PRODEGESP/UFSC?

Para tanto, os resultados obtidos com as entrevistas e aplicação dos questionários culminaram na apresentação das competências mais requeridas e menos presentes nos gestores, sendo passíveis de desenvolvimento por meio das ações de capacitação oferecidas pela UFSC. Não obstante, sempre é importante lembrar que as ações de capacitações 
representam apenas uma forma de desenvolvimento de competências, uma vez que estas podem ser aprendidas, modificadas e melhoradas por meio de outras experiências, como acrescentou o E4 (2017):

"são diversas as características que compõem o gestor; muitas podem ser aprendidas por capacitação ou formação oficial; outras são habilidades da pessoa mesmo, que tu vais aprender por observação, por comportamento, por vivência (...) então, quando tu tens uma pró-reitora que tem uma atitude positiva, isso reflete nas atitudes dos subordinados, diretores, né?”.

Sabe-se, contudo, que implementar ações de capacitação com vistas ao desenvolvimento de competências representa um grande desafio para as instituições sobretudo as públicas (nestas, inclui-se a UFSC). Nesse sentido, faz-se necessária também uma reflexão sobre a dificuldade de inserção da gestão por competências neste modelo rígido de cargos e carreiras existente no cenário público brasileiro. Para além das contribuições aos diretores de departamento da PRODEGESP e à política de gestão de pessoas da UFSC, este trabalho fortalece a ideia de que a legislação pouco flexível a que estão submetidos os servidores públicos enfraquece a possibilidade de implementação de ferramentas que vislumbrem a sua qualificação, a exemplo da gestão por competências. Entretanto, permanecem vivas as evidências que proporcionam uma efetiva melhoria nas competências aqui compartilhadas e colaboram com o desenvolvimento de pessoas cujas competências caminhem na mesma direção que as da instituição.

Por fim, compreendendo que o número de gestores questionados restringiu-se àqueles ocupantes de cargos de chefia imediatamente subordinados aos diretores de departamento, sugere-se que a mesma sistemática aqui adotada seja novamente realizada abrangendo um público maior - talvez até todos os servidores da Pró-Reitoria -, contemplando as respostas de mais servidores, com o intuito de melhor embasar os resultados obtidos, uma vez que todos têm relação, ainda que não direta, com as chefias intermediárias estudadas.

Ademais, importante mencionar que a metodologia utilizada neste estudo pode ser replicada por outras Pró-Reitorias com estruturas funcionais semelhantes à PRODEGESP, haja vista a relevância do cargo ocupado junto ao dirigente máximo e também junto à sociedade de uma maneira geral. 


\section{REFERÊNCIAS}

ALMEIDA, S. M. Competências requeridas aos gestores em cargos de direção do Instituto Federal Catarinense - Campus Camboriú. Dissertação (Mestrado Profissional em Administração) - Universidade Federal de Santa Catarina, Florianópolis, 2013.

AMARAL, H. K. Desenvolvimento de competências de servidores na administração pública brasileira. Revista do Serviço Público, p. 549-563, 2006.

ANDRADE, M. V. M.; SANTOS, A. R. Gestão de pessoas no serviço público federal: o caso do núcleo de documentação da universidade federal fluminense. Anais do XIII Seminário Nacional de Bibliotecas Universitárias. Universidade Federal do Rio Grande do Norte, Natal, 2004. Disponível em:

http://www.ndc.uff.br/OLD2013/repositorio/Gest\%E3o\%20de\%20pessoas\%20no\%20Servi\% E7o\%20P\%FAblico.pdf. Acesso em: 21fev. 2017.

ANTONELLO, C. S.; PANTOJA, M. J. Aprendizagem e o desenvolvimento de competências. In: PANTOJA, M. J.; CAMÕES, M. R. S.; BERGUE, S. T. (Orgs.). Gestão de pessoas: bases teóricas e experiências no setor público. Brasília: ENAP, 2010, p. 51-102.

ARAÚJO, K., GALEANO, R., VIEIRA, V.A. A qualidade de vida no trabalho como fator de influência no desempenho organizacional. Disponível em:

http://www.ead.fea.usp.br/semead/11semead/resultado/an_resumo.asp?cod_trabalho=759. Acesso em: 24 set. 2015.

BERGUE, S. T. Modelos de gestão em organizações públicas: teorias e tecnologias para análise e transformação organizacional. Caxias do Sul: Educs, 2011.

BRANDÃO, H. P. Mapeamento de competências: métodos, técnicas e aplicações em gestão de pessoas. São Paulo: Atlas, 2012.

BRANDÃO, H. P BAHRY, C. P. Gestão por competências: métodos e técnicas para mapeamento de competências. Revista do Serviço Público - RSP, v. 56, n. 2, p. 179-194, 2005 .

BRANDÃO, H. P ; BORGES-ANDRADE, J. E. Causas e efeitos da expressão de competências no trabalho: para entender melhor a noção de competência. Revista de Administração Mackenzie, v. 8, n. 11, p. 32-49, 2007,

BRASIL. Decreto no 5.707, de 23 de fevereiro de 2006. Institui a Política e as Diretrizes para o Desenvolvimento de Pessoal da administração pública federal direta, autárquica e fundacional, e regulamenta dispositivos da Lei $\mathrm{n}^{\mathrm{o}}$ 8.112, de 11 de dezembro de 1990 .

Disponível em:

REAd I Porto Alegre - Vol. 25 - No 1 - Janeiro / Abril 2019 - p. 83-115 
http://www.planalto.gov.br/ccivil_03/_Ato20042006/2006/Decreto/D5707.htm. Acesso em:

22 jul. 2016.

BRASIL. Portaria no 208, de 23 de julho de 2006a. Dispõe sobre os instrumentos da Política Nacional de Desenvolvimento de Pessoal.

CARBONE, P. P.; BRANDÃO, H. P; LEITE, J. B. D.; VILHENA, R. M. P. Gestão por competências e gestão do conhecimento. 3a . ed. Rio de Janeiro: Editora FGV, 2009.

CARLETTO, B. Competências essenciais requeridas para o gerenciamento das linhas de produção da indústria alimentícia: a visão dos seus gestores. Dissertação (Mestrado) Programa de Pós-graduação em Engenharia da Produção, Universidade Tecnológica Federal do Paraná, Ponta Grossa, 2006.

DALMAU, M. B. L. D. Competências gerenciais requeridas aos gestores de nível intermediário nas Instituições Federais de Ensino de Santa Catarina. Projeto de Pesquisa CAPES. Florianópolis, 2014.

DUTRA, J. S. Competências: conceitos e instrumentos para a gestão de pessoas na empresa moderna. São Paulo: Atlas, 2007.

ENAP - ESCOLA NACIONAL DE ADMINISTRAÇÃO PÚBLICA. Política Nacional de Desenvolvimento de Pessoal. 2017. Disponível em:

http://antigo.enap.gov.br/downloads/pndp.pdf. Acesso em: 21 fev. 2017.

FÁVERO, M. L. A. A Universidade no Brasil: das origens à Reforma Universitária de 1968. In: Educar, Curitiba, n. 28, p. 17-36, 2006. Editora UFPR. Disponível em: www.scielo.br/pdf/er/n28/a03n28.pdf. Acesso em: 14 fev. 2017. FISCHER, A. L.; DUTRA, J. S.; NAKATA, L. E.; RUAS, R. Absorção do conceito de competência em gestão de pessoas: a percepção dos profissionais e as orientações adotadas pelas empresas. In: DUTRA, J. S.; FLEURY, M. T. L; RUAS, R. (Orgs.), Competências: conceitos, métodos e experiências. São Paulo: Atlas, 2010, p. 31-50.

FLEURY, M. T. L; FLEURY, A. Construindo o conceito de competência. Revista de Administração Contemporânea, v. 5, n. esp, p. 183-196, 2001.

GIL, A. C. Como elaborar projetos de pesquisa. 4. Ed. São Paulo: Atlas, 2002.

GRILLO, A. N. Gestão de Pessoas: princípios que mudam a Administração Universitária. Florianópolis: UFSC/CAD, 2001.

HARB, A. G. As competências organizacionais nos segmentos de hipermercado e supermercado no Brasil. Tese (Doutorado em Engenharia de Produção) - Programa de PósGraduação em Engenharia de Produção, Universidade Federal de Santa Catarina, Florianópolis, 2011. 
IFSC. Plano Anual de Capacitação. 2017. Disponível em:

https://intranet.ifsc.edu.br/images/file/DGP/capacitacao/TAE-

Reitoria/PLANO_ANUAL_DE_CAPACITACAO_2016.pdf. Acesso em: 27 jun. 2017.

LANA, M. S.; FERREIRA, V. C. P. Gestão por competências: impactos na gestão de pessoas. Estação Científica Online. Juiz de Fora, n. 4, abr./mai., 2007. Disponível em: http://victorparadela.com/Artigos/Artigo\%20GC.pdf. Acesso em: 23 fev. 2017.

LAVARDA, R. A. B.; CANET-GINER, M. T.; PERIS-BONET, F. J. How middle managers contribute to strategy formation process: connection of strategy processes and strategy practices. Revista de Administração de Empresas. v. 50, n. 4, p. 358-370, 2010.

LEAL, F. G. Competências secretariais requeridas pela Universidade Federal de Santa Catarina. Dissertação (Mestrado em Administração) - Programa de Pós-Graduação em Administração, Universidade Federal de Santa Catarina, Florianópolis, 2015.

MACHADO, J. A.; LAVARDA, R. A. B. Os Papéis que o Middle Manager Desempenha na Formação e Implementação da Estratégia. Anais ...V Encontro de Estudos em Estratégias. Porto Alegre, RS, 2011. Disponível em:

http://www.anpad.org.br/diversos/trabalhos/3Es/3es_2011/2011_3ES329.pdf. Acesso em: 06 mar. 2017.

NONAKA, I. Toward middle-up-down management: accelerating information creation. MIT Sloan Management Review. Abr. 1988. Disponível em:

http://sloanreview.mit.edu/article/toward-middleupdown-management-acceleratinginformation-creation. Acesso em: 06 mar2017.

PELISSARI, A. S.; GONZALEZ, I. V. F. P.; VANALLE, R. M. Competências gerenciais: um estudo em pequenas empresas de confecções. Revista Eletrônica de Administração. Porto Alegre, v. 17, n. 1, p. 149-180, 2011.

PUCCI, V. R. Competências gerenciais: significado e importância. Dissertação (Mestrado em Administração) - Programa de Pós-Graduação em Administração, Universidade Federal de Santa Catarina, Florianópolis, 2000.

ROCHA, G. B.; SHINYASHIKI, G. T.; PASSADOR, C. S. Gestão de Pessoas em uma Universidade Pública Brasileira: conflito na Mudança do Modelo de Gestão. XXXVI

Encontro da Anpad. Rio de Janeiro, 2012. Disponível em: http://www.anpad.org.br/admin/pdf/2012_EOR919.pdf. Acesso em: 20 fev2017. RODRIGUES, I. A UFSC na década de 1960: outras histórias. UFSC 50 anos: trajetórias e desafios. In: NECKEL, R.; KÜCHLER, A. D. C. (Orgs.). Florianópolis: UFSC, 2010, p. 1735 . 
RUAS, R. L. Gestão por competências: uma contribuição à estratégia das organizações. In: RUAS, R. L.; ANTONELLO, C. S.; BOFF, L. H. Aprendizagem organizacional e competências. Porto Alegre: Bookman, 2005.

SARTORETTO, M. F. A. T. Competências gerenciais: um estudo na Universidade Federal da Fronteira Sul. Trabalho de Conclusão de Curso (Bacharelado em Administração). Universidade Federal da Fronteira Sul, Chapecó, 2016.

SILVA, E. L.; MENEZES, E. M. Metodologia da pesquisa e elaboração de dissertação. Florianópolis: UFSC, 2005.

SOUZA, I. M.; KOBIYAMA, A. R. C. E. Políticas de gestão de pessoas para as universidades federais. X Colóquio Internacional sobre Gestión Universitaria en América del Sur. Disponível em: https://repositorio.ufsc.br/bitstream/handle. Acesso em: 21 fev 2017. SOUZA, J. G. Evolução histórica da Universidade Brasileira: abordagens preliminares. Revista da Faculdade de Educação PUCCAMP, v. 1, n. 1, p. 42-58, ago/1996. TOSTA, H. T. Competências gerenciais requeridas aos gestores intermediários da Universidade Federal da Fronteira Sul. Dissertação (Mestrado em Administração) Programa de Pós-Graduação em Administração, Universidade Federal de Santa Catarina, Florianópolis, 2011.

TRIVIÑOS, A. N. S. introdução à pesquisa em ciências sociais: a pesquisa qualitativa em educação. São Paulo: Atlas, 2012.

UFBA. Plano Anual de Capacitação. 2016. Disponível em:

https://capacitar.ufba.br/sites/capacitar.ufba.br/files/plano_de_capacitacao_2016_0.pdf. Acesso em: 27 jun2017.

UFSC. Apresentação da Prodegesp. 2017. Disponível em: http://prodegesp.ufsc.br/. Acesso em: 22 jan 2017.

UFSC. Plano de Desenvolvimento Institucional 2015 a 2019. Universidade Federal de Santa Catarina. 2015. Disponível em: http://pdi.ufsc.br/files/2015/05/PDI-2015-2019-1.pdf. Acesso em: 08 jun 2017.

UNB. Plano Anual de Capacitação. Disponível em:

http://www.capacitacao.unb.br/images/PAC_2017_diagramado.pdf. Acesso em: 27 jun 2017. VERGARA, S. C. Métodos de pesquisa em Administração. 5. Ed. São Paulo: Atlas, 2012. YIN, R. K. Estudo de caso: planejamento e métodos. 4. Ed. Porto Alegre: Bookman, 2010. 